\title{
Eksistensi Tennung Walida (Gedogan) Kain Sutera Di Desa Rumpia Kecamatan Majauleng Kabupaten Wajo
}

\author{
Firdaus \\ Pendidikan Sosiologi, Universitas Muhammadiyah Makassar \\ Email: firdausos@unismuh.ac.id / dhaus.sosio@gmail.com
}

\begin{abstract}
This study aims to reveal the existence of the use of weaving walida (gedogan) tools in the process of making silk cloth in Rumpia Village, Majauleng District, Wajo Regency. The type of research used is descriptive qualitative. Data was collected by means of observation, interviews, and documentation. Data analysis uses data reduction, data presentation, and drawing conclusions. The results showed that the existence of Tennung Walida in Rumpia Village still exists and is used by several weaver communities because the woven fabrics produce high quality and selling prices and there are still consumers who order fabrics woven using Tennung Walida. As for the public perception about the use of Tennung Walida in the modernization era in Rumpia Village, it can still be used by the weaver community because until now, Tennung Walida users continue to pass on their knowledge of using Tennung Walida to their children and continue to maintain and care so that they can still be used and remain part of the community. from his life, although currently Tennung Walida has begun to decrease because of the more modern looms that have been widely circulated at this time as well as the types of contemporary businesses that are more in demand by the public.
\end{abstract}

Keywords: Existence; Tennung Walida; Silk Fabric.

Abstrak. Penelitian ini bertujuan mengungkapkan eksistensi penggunaan alat tennung walida (gedogan) dalam proses pembuatan kain sutera di Desa Rumpia Kecamatan Majauleng Kabupaten Wajo. Adapun jenis penelitian yang digunakan ialah deskriptif kualitatif. Pengumpulan data dilakukan dengan teknik observasi, wawancara, dan dokumentasi. Analisis data menggunakan reduksi data, penyajian data, dan penarikan kesimpulan. Hasil penelitian menunjukkan bahwa eksistensi Tennung Walida di Desa Rumpia masih tetap ada dan digunakan oleh beberapa masyarakat penenun dikarena kain yang di tenun menghasilkan kualitas serta harga jual yang tinggi serta masih ada masyarakat konsumen yang memesan kain yang di tenun menggunakan Tennung Walida. Adapun persepsi masyarakat tentang penggunaan Tennung Walida di era modernisasi di Desa Rumpia, masih dapat digunakan oleh masyarakat penenun karena sampai saat ini pengguna tennung walida tetap mewariskan pengetahuannya menggunakan Tennung Walida kepada anak-anaknya dan terus memelihara dan merawat agar masih dapat digunakan dan tetap menjadi bagian dari kehidupannya, meskipun saat ini Tennung Walida sudah mulai berkurang karena adanya alat tenun yang lebih Modern yang sudah banyak beredar saat ini serta adanya jenis usaha kekinian yang lebih diminati masyarakat.

Kata Kunci : Eksistensi; Tennung Walida; Kain Sutera.

\section{PENDAHULUAN}

Negara Indonesia merupakan negara kepulauan yang besar yang saling sambung menyambung dari sabang sampai merauke dan masing-masing daerahnya memiliki kebudayaan yang berbedabeda, dan kebudayaan yang berbeda-beda tersebut yang menjadi ciri khas setiap daerahnya masingmasing. Indonesia terkenal negara yang memiliki budaya yang beranekaragam, selain itu juga dikenal sebagai negara dengan lingkungan sosial budaya yang ditandai dengan nilai-nilai kehidupan yang ramah, orang-orang yang memegang sopan santun, dan juga masyarakat yang damai. 
Kebudayaan merupakan suatu warisan yang perlu kita banggakan, sebab kebudayaan merupakan ciri atau penanda dari setiap suku atau daerah itu sendiri yang perlu kita jaga dan sangat perlu kita lestarikan. E.B. Tylor, dalam penulis buku ternama "Primitive Culture" ini, pernah mengemukakan bahwa kebudayaan atau peradaban merupakan suatu keseluruhan yang kompleks mencakup pengetahuan, kepercayaan, kesenian, moral, hukum, adat-istiadat, dan lain-lain kemampuan-kemampuan serta kebiasaan-kebiasaan yang didapatkan oleh manusia sebagai anggota masyarakat (Tylor, 1924).

Hingga saat ini indonesi memiliki begitu banyak kebudayaan yang diakui dunia. Contohnya, kain Batik yang telah diakui UNESCO. Tapi tidak banyak orang tahu bahwa Indonesia juga memiliki tenun, songket, sutera, dan lain-lain sebagai warisan budaya kain tradisional khas Indonesia.

Dan jika di telusuri lebih dalam begitu banyak daerah di Indonesia yang masyarakatnya sudah sejak dulu mengenal teknik menenun dan terus mereka kembangkan. Sehingga di setiap daerah di Indonesia memiliki teknik menenun yang berbeda, mulai dari memilih benang, warna, dan motif.

Sulawesi merupakan salah satu pulau besar di tengah-tengah Indonesia yang memiliki berbagai macam warisan kebudayaan seperti kain tenun sutera Sulawesi. Kain tenun sutera Sulawesi, disebut juga Lipa' Sabbe yang dalam bahasa bugis, lipa' berarti sarung dan Sabbe' berarti sutera. Dalam pembuatan benang sutera itu sendiri hingga menjadi kain sutera masih menggunakan alat tenun tradisional.

Sulawesi selatan khusunya Di kabupaten Wajo dikenal sebagai penghasil sutera terbesar di Sulawesi Selatan. Sebab kegiatan menenun merupakan aktifitas keseharian masyarakat bugis Wajo dari jaman nenek moyang. Kegiatan menenun sutera di bawah rumah tiap penduduk adalah tradisi yang dilakukan orang bugis.

I Ketut Gobyah Thiam (2003), mengatakan bahwa kearifan lokal adalah kebenaran yang telah mentradisi dalam suatu daerah. Seiring berjalannya waktu serta berkembangnya zaman, tradisi atau kebudayaan yang dipegang teguh oleh masyarakat kini sudah hampir punah. Karena masyarakat lebih memilih dan menampilkan budaya modern yang kebanyakan berasal dari budaya asing yang belum tentu sesuai dengan kepribadian masyarakat tersebut.

Yang menjadi kelebihan dari tenun sutera Bugis-Wajo adalah proses memproduksinya, untuk menghasilkan hasil tenun orang Bugis Wajo setiap pengrajin memelihara dan mengembangkan sendiri ulat sutera untuk menghasilkan benang sutera. Benang sutera yang dihasilkan pun merupakan hasil persilangan ulat sutera jepang dengan ulat sutera cina sehingga hasil kain tenun sutera bugis wajo lebih halus, mengkilap dan tahan lama.

Dari benang sutera yang dihasilkan kemudian ditenun sehingga menjadi sebuah kain yang utuh. Proses penenunan dapat dilakukan dengan menggunakan alat tenun yang bernama Tennung Walida (gedogan). Tennung Walida merupakan alat tenun tradisional yang dioperasikan dengan posisi duduk dan meluruskan kaki ke depan, tennung walida dapat menghasilkan kain sutera yang sangat berkualitas tinggi karena proses pengerjaannya yang sangat cermat dan teliti.

Tennung walida merupakan alat tenun tradisioal yang dapat menghasilkan kain sutera yang berkualitas tinggi. Karena pada proses pembuatan memerlukan ketelitian yang tinggi oleh penenun. Meskipun memerlukan waktu yang cukup lama, dengan menggunakan tennung walida maka kain sutera akan tetap terjaga kualitasnya, serta tradisi menenun dapat terus diturunkan dari generasi ke generasi serta eksistensinya tetap terjaga.

Tennung Walida (gedogan) merupakan alat tenun pertama yang digunakan masyarakat dikabupaten wajo dalam membuat kain sutera, yang dapat menghasilkan kain berkualitas tinggi karena proses pengerjaannya yang memerlukan ketelitian dari penenunnya. Dan karena kualitas kain suteranya yang tinggi sahingga Kabupaten Wajo dapat dikenal dengan sebutan Kota sutera, dan diharapkan Tennung Walida (Gedogan) dapat menjadi salah satu ikon kabupaten wajo yang menghasilkan kain sutera berkualitas tinggi.

Seiring berkembangnya zaman Tennung Walida (Gedogan) yang menjadi alat tradisional pertama dan merupakan warisan budaya yang digunakan dalam membuat kain tenun sutera kini mulai disandingkan dengan beberapa alat tenun yang lebih canggih dan bahkan menggunakan 
mesin. Sehingga, nilai-nilai budaya dalam pembuatan dan penggunaan kain tenun sutera mulai merosot. Maka dari itu berdasarkan uraian di atas, maka penulis termotivasi untuk melakukan penelitian guna memperoleh informasi yang lebih akurat mengenai warisan budaya Eksistensi Tennung Walida (gedogan) kain sutera di Desa Rumpia Kecamatan Majauleng Kabupaten Wajo.

\section{METODE PENELITIAN}

Adapun jenis penelitian yang digunakan ialah deskriptif kualitatif, yaitu penelitian dengan memberikan gambaran secara jelas dan sistematis terkait dengan objek yang diteliti. Penentuan informan dalam penelitian ini dilakukan dengan teknik purposive sampling, dan juga menggunakan sumber data primer dan sekunder, teknik pengumpulan data yaitu observasi, wawancara, dan dokumentasi, kemudian dianalisis melalui tahapan pengorganisasian data, pengelompokan data, menguji asumsi terhadap permasalahan yang ada terhadap data, mencari alternatif penjelasan data, menuliskan hasil penelitian, sedangkan teknik keabsahan datanya menggunakan triangulasi sumber, waktu dan teknik.

\section{HASIL PENELITIAN DAN PEMBAHASAN}

Penelitian ini dilakukan dengan cara melakukan pengamatan secara langsung di daerah sekitaran Desa Rumpia Kecamatan Majauleng Kabupaten Wajo untuk mengetahui dan melihat eksistensi budaya menenun didesa tersebut dan juga dilakukan wawancara singkat terhadap beberapa masyarakat Desa Rumpia seperti Kepala desa serta masyarakat sekitar.

\section{Eksistensi Tennung Walida (Gedogan) Kain Sutera di Desa Rumpia Kecamatan Majauleng Kabupaten Wajo}

Berdasarkan pengamatan yang telah dilakukan Di Desa Rumpia Kecamatan Majauleng Kabupaten Wajo didapatkan bahwa di desa tersebut memiliki beragam budaya, salah satunya budaya menenun yang menjadi aktivitas sehari-hari masyarakat khususnya kaum wanita di Desa Rumpia. Salah satu keunikan dalam aktivitas menenun masyarakat yaitu menggunakan alat tenun tradisional yang biasa masyarakat sebut Tennung Walida. Tennung Walida ini merupakan alat tenun tradisional yang sudah ada di Kabupaten Wajo sejak Abad ke-13. Tennung Walida digunakan untuk menenun benang sutera menjadi sebuah kain yang dapat dibuat menjadi baju, celana, atau sarung. Tennung Walida digunakan dengan cara dipangku, dan dalam proses menenun menggunakan Tennung Walida dibutuhkan ketelitian dan keuletan yang tinggi dimulai dari proses merapikan dan menyusun benang yang harus dilakukan satu persatu, proses penyesuaian motif, hingga masuk kedalam tahap proses menenun sehingga hasil yang diinginkan bisa didapatkan dan juga memuaskan. Dahulu Tennung Walida merupakan satu-satunya alat tenun kain sutera yang digunakan masyarakat penenun yang ada di Kabupaten Wajo.

Seiring berjalannya waktu alat tenun terus berkembang sehingga muncul alat tenun model baru yang biasa masyarakat sebut Tennung Bola-bola (ATBM). Sehingga membuat tennung walida harus bersaing dengan alat tenun yang lebih modern. Namun sampai sekarang meski dengan berkembangnya teknologi, masih ada masyarakat yang mau menggunakan tennung walida, selain dari faktor kebiasaan yang telah dipelajari dari kecil, ada juga faktor yang mendukung tennung walida sehingga masih bertahan sampai sekarang yaitu nilai kualitas kain yang dihasilkan oleh tennung walida. Meksipun menggunakan alat tradisional dan memerlukan proses yang sangat panjang dalam menenun tetapi menggunakan tennung walida dapat menjadi pelajaran bagi penenun dalam hal bersabar, keuletan, ketelitian, serta keterampilan dalam menenun sehingga menghasilkan kain tenun yang berkualitas sangat tinggi dengan nilai jual yang tinggi pula.

Dari hasil penuturan pemerintah Desa, bahwa budaya menenun menggunakan Tennung Walida yang dilakukan oleh masyarakat masih dapat dijumpai di sekitar Desa Rumpia. Akan tetapi penggunaan Tennung Walida perlahan mulai digantikan oleh alat tenun yang lebih modern seperti Tennung Bola-bola atau biasa disebut ATBM. Selain bersaing dengan alat tenun yang lebih modern tennung walida juga harus bersaing dengan banyaknya jenis pekerjaan lain yang lebih diminati masyarakat terutama anak muda sekarang seperti membuat dan menjual makanan dan minuman 
kekinian. Apalagi dengan adanya media seperti sekarang masyarakat jadi lebih mudah dalam memasarkan produknya. Ada pun hal yang dilakukan oleh pemerintah Desa Rumpia agar budaya menenun menggunakan tennung walida tetap eksis dan terjaga yaitu berupa memberikan bantuan biaya perawatan alat tenun, Serta masyarakat diharapkan ikut membantu dalam mempertahankan dan menjaga budaya ini salah satunya dengan cara melalui media informasi.

Plato berpendapat bahwa esensi lebih nyata dari pada kalau berpartisipasi dalam materi dan bila mengasimilasikan eksistensi pada esensi maka materi akan berasosiasi dengan bukan ada. Keberadaan alat Tennung Walida di Desa Rumpia Kecamatan Majauleng Kabupaten Wajo sampai sampai saat ini masih ada deretan penenun menggunakan Tennung Walida meskipun sudah tidak sebanyak dulu. Selain itu juga masih ada konsumen yang menginginkan kain sutera yang ditenun menggunakan Tennung Walida.

Namun saat ini penenun yang menggunakan Tennung Walida di Desa Rumpia Kecamatan Majauleng Kabupaten Wajo kebanyakan hanya Ibu Rumah Tangga dan Orang tua yang telah berumur panjang dan masih mampu menenun, dikarenakan kebanyakan gadis desa lebih berfokus dalam menempuh pendidikan atau membuat usaha kekinian. Didalam alat Tennung Walida terdiri dari beberapa komponen pendukung yang memiliki fungsi masing-masing antara lain Bokoreng yang berfungsi menjadi sandaran penenun, Wakkangen berfungsi untuk menggulung kain yang telah ditenun, Jakka digunakan untuk mengatur lusi bawah dan lusi atas, Walida berfungsi untuk merapatkan benang, pattolo are berfungsi untuk mengangkat benang agar teratur, awereng dan palapa berfungsi untuk mengatur motif yang dinginkan, fappacenre digunakan untuk menekan benang bawah, allulungeng digunakan untuk menggulung benang, fappejelloreng berfungsi sebagai dudukan walida, taropeng digunakan untuk memasukkan benang yang akan disatukan, dan saureng berfungsi untuk menyusun benang sebelum masuk dalam proses menenun. Dan setiap komponen difungsikan secara manual sehingga menenun menggunakan Tennung Walida memerlukan waktu yang lama dan ketelitian yang tinggi sehingga kain yang dihasilkan berkualitas tinggi serta dijual dengan harga yang lumayan tinggi.

Spencer membedakan antara pertumbuhan budaya dan perkembangan budaya. Pertumbuhan adalah proses pertambahan, sedangkan perkembangan mengandung pengertian transformasi struktur. Selain itu, perubahan yang terjadi pada Tennung Walida bukan menjadi masalah bagi masyarakat penenun karena mereka paham bahwa di era modernisasi akan ada alat tenun yang lebih canggih. Tennun Walida ada sejak abad ke-13 hingga sampai pada saat ini namun tetap eksis dikalangan masyarakat di Desa Rumpia Kecamatan Majauleng Kabupaten Wajo.

Tennung Walida memiliki nilai jual yang lebih tinggi dibanding alat tenun lainnya karena kualitas yang dihasilkan lebih bagus dan bahan yang digunakan lebih baik. Tennung walida sudah sangat sulit didapatkan karena memang merupakan alat tenun tradisional disamping itu masyarakat berharap agar tennung walida terus digunakan karena banyaknya nilai nilai sosial dan budaya yang terkandung didalam penggunaan tennung walida. Secara substansial, kearifan lokal adalah nilai-nilai yang berlaku dalam masyarakat. Nilai-nilai yang diyakini sebagai kebenaran dan menjadi referensi dalam berperilaku komunitas lokal sehari-hari. Oleh karena itu, sangat masuk akal jika Greertz (1981) mengatakan bahwa kearifan lokal adalah entitas yang sangat menentukan harkat dan martabat manusia dalam komunitasnya. Ini berarti bahwa kearifan lokal yang mengandung unsur-unsur kecerdasan, kreativitas dan pengetahuan lokal tentang Eliets dan masyarakat menentukan dalam pembangunan peradaban masyarakat.

\section{Persepsi Masyarakat Tentang Penggunaan Tennung Walida (Gedogan) Di Era Modernisasi}

Persepsi merupakan proses seseorang untuk menerima informasi melalui panca indranya. Baik melalui penglihatan, pendengaran, penghayatan, perasaan, dan penciuman. Kemudian rangsangan terhadap alat indra diatur untuk dilakukan perorganisasian dan penafsiran. Proses penafsiran pada setiap individu tidak sama terhadap informasi yang diterima. Sebagaimana pendapat David Krech yang dikutip dari Miftah Thoha (2011), bahwa persepsi merupakan bagian dari peta kognitif individu yang bukanlah penyajian potografik dari suatu kenyataan fisik, melainkan agak bersifat kontruksi 
pribadi yang kurang sempurna mengenai obyek tertentu, diseleksi sesuai dengan kepentingan utamanya dan dipahami menurut kebiasaannya.

Seiring berkembangnya zaman penggunaan tennung walida di Desa Rumpia Kecamatan Majauleng Kabupaten Wajo kini sudah menurun dikarenakan munculnya alat tenun yang lebih mudah digunakan dan lebih cepat dalam menyelesaikan kain tenun seperti tennung bola-bola dan tenun mesin. Sehingga banyak orang lebih memilih untuk mempelajari tennung bola-bola. Akan tetapi meskipun tennung walida merupakan alat tenun tradisional pertama sampai saat ini masih ada masyarakat yang menggunakannya dikarenakan memang kualitas kain yang di hasilkan sangat tinggi sehingga harga jualnya pun lebih mahal dua kali lipat dari harga kain yang ditenun menggunakan tennung bol-bola.

Selo Soemardjan dan Soelaman Soemardi dalam bukunya Soerjono Soekanto (2014). Perubahan terjadi karena ada faktor baru yang lebih memuaskan masyarakat sebagai pengganti faktor yang lama. Mungin juga masyarakat mengadakan perubahan karena terpaksa demi untuk menyesuaikan suatu faktor dengan faktor-faktor lain yang sudah mengalami perubahan terlebih dahulu. Pada umumnya dapat dikatakan bahwa mungkin ada sumber sebab-sebab tersebut yang terletak didalam masyarakat itu sendiri dan ada yang letaknya dari luar. Menurut masyarakat di Desa Rumpia Kecamatan Majauleng berkurangnya budaya menenun menggunakan Tennung Walida di era modernisasi saat ini yang pertama yaitu masuknya alat tenun yang lebih modern yang lebih cepat dan lebih mudah dioperasikan oleh masyarakat penenun, yang kedua remaja yang lebih fokus dalam pendidikan atau bersekolah, dan yang ketiga banyaknya jenis pekerjaan atau usaha yang kekinian yang digeluti remaja saat ini.

Zainal Arifin dalam bukunya Ilmu Sosial Budaya Dasar (2012). Salah satu konsep bahwa masyarakat tidak lain dari orang yang perorang yang hidup bersama yang menghasilkan kebudayaan. Lalu masyarakat merupakan pendukung, pemelihara, pengembang, dan mewariskan kebudayaan tersebut kepada generasi berikutnya. Secara ekstrim bisa dikatakan sebagai cultural determination, yang berarti segala aspek yang menjadi bagian dari suatu masyarakat. Eksistensi atau keberadaannya ditentukan oleh kebudayaan dan tradisi yang dimiliki serta didukung oleh masyarakat tersebut. Menurut masyarakat di Desa Rumpia Kecamatan Majauleng Kabupaten Wajo sampai saat ini penggunaan Tennung Walida di era modernisasi masih dapat digunakan oleh masyarakat penenun karena sampai saat ini pengguna tennung walida tetap mewariskan pengetahuannya menggunakan Tennung Walida kepada anak-anaknya dan terus memelihara dan merawat alat tenunnya agar masih dapat digunakan dan tetap menjadi bagian dari kehidupannya.

Menurut Kluckhon dan Strodberck soal-soal yang paling tinggi nilainya dalam kehidupan manusia dan yang ada dalam tiap kebudayaan di dunia ini menyangkut paling sedikit lima hal, yakni (1) Human Nature atau makna hidup manusia; (2) Man Nature atau persoalan hubungan manusia dengan alam sekitarnya; (3) Persoalan Waktu, atau persepsepsi manusia terhadap waktu; (4) Persoalan Aktivitas 'Activity', persoalan mengenai pekerjaan, karya dan amal perbuatan manusia; dan (5) Persoalan Relasi 'Relationality' atau hubungan manusia dengan manusia lainnya. Berkaitan dengan apa yang di dapatkan dalam penelitian tentang Tennung Walida ini dan persepsi yang diungkapkan oleh para narasumber sehingga dapat dikatakan nilai budaya yang ada pada aktifitas menenun menggunakan Tennung Walida masih sangat tinggi di era modernisasi karena menjadi alat yang masih bermakna terhadap kehidupan para pengguna Tennung Walida sehingga para penenun dapat menenun dan menumpahkan karya-karyanya didalam kumpulan benang yang ditenun sehingga menjadi kain yang begitu berkualitas tinggi, sehingga mampu menjadi salah satu sumber penghasilan bagi para Penenun Pengguna Tennung Walida, dan tentu saja dengan barang atau kain yang berkualitas akan menimbulkan kesan bangga tersendiri apabila memakainya.

Menurut Robert H. Lauer. Teori Perkembangan, yaitu linear perubahan yang berkembang menuju suatu titik tertentu, seperti perubahan dari masyarakat tradisional ke masyarakat modern yang lebih kompleks. Perubahan sosial menurut pola linear, masyarakat berkembang dari semula primitif, tradisional dan menjadi modern teori ini dilihat dari sudut pandang tradisional primitif masyarakat modern. Keterkaitan antara teori dengan penelitian ini dapat kita lihat seperti yang 
terjadi di era modernisasi saat ini yang membawa dampak positif maupun negatif dalam pembuatan Kain Tenun Sutera. Seperti masyarakat khususnya kaum perempuan dan ibu rumah tangga yang dulunya menenun menggunakan Tennung Walida mulai perlahan-lahan beralih ke alat tenun yang lebih modern. Dengan proses menyelesaikan tenun yang cepat serta mudah untuk digunakan alat tenun modern tentu tidak hanya memiliki kelebihan namun juga memiliki kekurangan antaranya dapat menurunkan nilai kualitas dari suatu kain sutera.

Dari hasil wawancara dari semua narasumber yang ada, penulis dapat menyimpulkan bagaiamana perspektif masyarakat terhadap penggunaan Tennung Walida di era modernisasi yang ada di Desa Rumpia Kecamatan Majauleng Kabupaten Wajo. Bahwa, sampai saat ini masih layak untuk digunakan dan memang masih ada yang menggunakan, selain menghasilkan kain sutera yang berkualitas tinggi juga dalam proses menenun menggunakan tennung walida juga terdapat nilai nilai sosial dan budaya didalamnya. Walaupun pada kenyataannya penggunaan tennung walida telah berkurang dikarenakan masuknya alat tenun yang lebih modern yang proses pengerjaan kain tenunnya lebih cepat dibandingkan dengan Tennung Walida, pengguna tennung walida juga harus tetap menjaga kualitasnya dalam menenun agar keunggulannya tetap terjaga. Harapan masyarakat yang masih tetap eksis menggunakan tennung walida, kelak pemerintah dan masyarkat dapat bekerja sama seperti membuat ruang pamer serta memperkenalkan melalui media informasi sehingga tennung walida tetap terjaga dan tidak hilang.

\section{KESIMPULAN}

Eksistensi Tennung Walida (gedogan) kain sutera di Desa Rumpia Kecamatan Majauleng Kabupaten Wajo. Dari rumusan masalah penelitian ini menunjukkan bahwa Eksistensi Tennung Walida di Desa Rumpia masih tetap ada dan digunakan oleh beberapa masyarakat penenun dikarena kain yang di tenun menghasilkan kualitas serta harga jual yang tinggi serta masih ada masyarakat konsumen yang memesan kain yang di tenun menggunakan Tennung Walida. Persepsi masyarakat tentang penggunaan Tennung Walida (gedogan) di era Modernisasi. Dari rumusan masalah penelitian ini menunjukkan bahwa Persepsi masyarakat tentang penggunaan Tennung Walida di era modernisasi di Desa Rumpia sampai saat ini masih layak untuk digunakan karena ketahanan dari alatnya dan memang masih ada masyarakat yang menggunakan alat Tennung Walida ini. Meskipun saat ini Tennung Walida sudah mulai berkurang karena adanya alat tenun yang lebih Modern yang sudah banyak beredar saat ini serta adanya jenis usaha kekinian yang lebih diminati masyarakat.

\section{DAFTAR PUSTAKA}

Ajman Satori, Aan Komariah. 2013. Metodologi Penelitian Kualitatif, Alfabeta, Bandung.

Akil, Sulfiana, Besse. 2019. Analisis Penerapan Tenaga Kerja Industri Tenun Sutera Di Desa Pakanna Kecamatan Tanasitolo Kabupaten Wajo.

Akil, Sulfiana, Besse. 2019. Analisis Penerapan Tenaga Kerja Industri Tenun Sutera Di Desa Pakanna Kecamatan Tanasitolo Kabupaten Wajo.

Arifin Zainal. 2012. Ilmu Sosial Budaya Dasar. Makassar: Anugrah Mandiri.

Crain, William. 2007. Theories of Development: Concepts and Applications, 3rd ed., terj. Yudi Santoso, Teori Perkembangan: Konsep dan Aplikasi, cet.1, Yogyakarta: Pustaka Pelajar,

Djam'an, S., \& Aan, K. 2010. Metodologi Penelitian Kualitatif. Bandung: alfabeta..

Gobyah, I. K. 2003. Berpijak pada Kearifan Lokal. Bali Pos, 4.

Guswandhi, Ferry dkk. 2018. Pengembangan ATBM (Alat Tenun Bukan Mesin) Menggunakan Sistem Dobby Elektronik. Volume 33 Nomor 29-36

Guswandhi, Ferry dkk. 2018. Pengembangan ATBM (Alat Tenun Bukan Mesin) Menggunakan Sistem Dobby Elektronik. Volume 33 Nomor 29-36

Hadi, S. dalam Sugiyono. 2012. Metode Penelitian Pendahuluan. Alfabeta, Bandung.

Khiyarusoleh, Ujang. 2016. "Konsep Dasar Perkembangan Kognitif Pada Anak Menurut Jean Piaget." DIALEKTIKA Jurnal Pemikiran Dan Penelitian Pendidikan Dasar 5.1. 
Kusuma, andi ima. 2018. Eksistensi Komunitas Penenun Bugis (Sebuah Refleksi Sosio-Kultural Masyarakat Wajo). Jurnal Walasuji, Volume 9 nomor 2.

Moleong, L. J., \& Edisi, P. R. R. B. 2004. Metodelogi penelitian. Bandung: Penerbit Remaja Rosdakarya.

Nasution, S. 1996. Metode Penelitian Naturalistik Kualitatif Tarsito.

Nurmeisarah, Trisna dkk. 2015. Tinjauan Tentang Tenun Tradisional Dusun Sade Desa Rambitan Kecamatan Pujut Kabupaten Lombok Tengah. Volume X

Rahman, N., \& Mariani, M. 2009. Kearifan lingkungan hidup manusia Bugis berdasarkan naskah Méong Mpaloé. La Galigo Press.

Robert H. Lauer, Perspektif Tentang Perubahan Sosial, Jakarta : Rineka Cipta, 1993.

Setiawan, Budiana, and RR Nur Suwarningdyah. 2014. "Strategi pengembangan tenun ikat kupang provinsi nusa tenggara timur." Jurnal Pendidikan dan Kebudayaan 20.3: 353-367.

Soekanto Soerjono dkk. 2014. Sosiologi Suatu Pengantar. Jakarta : PT Raja Grafindo Persada.

Sugiyono, D. 2008. Metode penelitian bisnis. Bandung: Pusat Bahasa Depdiknas.

Sugiyono, S. 2010. Metode penelitian kuantitatif dan kualitatif dan R\&D. Bandung: Alfabeta, CV.

Sulvianajayanti dkk. 2015. Makna Pesan Komunikasi Motif Kain Sutera Sengkang Pilihan Konsumen Di Kota Makassar. Volume 4 Nomor 1

Syukur, Muhammad dkk. 2014. Transformasi penenun bugis - wajo menuju era modernitas. Jurnal studi sejarah paramita, Volume 24 nomor 1

Tahara, tasrifin. 2013. Lipa Sabbe' Sengkang: Identitas dan Tantangan Teknologi Sarung Sutera Bugis.

Tylor, E. B. (1871). Primitive culture: Researches into the development of mythology, philosophy, religion, art and custom (Vol. 2). J. Murray.

Wahyuni Andi Dwi Eka. 2013. Motif Lipa Sabbe (Sarung Sutera) Sengkang Kabupaten Wajo Provinsi Sulawesi Selatan. Program S1 Pendidikan Tata Busana, Fakultas Teknik, Universitas Negeri Surabaya (UNS). E-Jurnal Vol.02. No.02 